\title{
DEVELOPING VALIDATION OF FOREST FIRE RISK MAPS BASED ON HISTORICAL FIRE INCIDENCES
}

\author{
Abdullah E. Akay*, Abdullah Erdoğan \\ Bursa Technical University, Faculty of Forestry, 16310 Yıldırım, Bursa, Turkey - abdullah.akay@ btu.edu.tr*
}

Commission VI, WG VI/4

KEY WORDS: Forest Fires, Fire Risk Maps, Map validation, GIS, MCDA, AHP.

\begin{abstract}
:
Large forest lands are damaged every year due to wild fires in Turkey. Prompt detection and rapid intervention is the key factors of firefighting activities. To be well prepared for the wildfires, it is crucial to determine the fire sensitive areas and then to locate fire extinguishing structures such as fire lookout towers and the firefighting headquarters by consideration these areas. The accuracy of the fire risk maps plays important role in the effectiveness of the fire management strategies and decisions. In this paper, the accuracy of a fire risk map, which was developed by GIS techniques integrated with Multi-Criteria Decision Analysis (MCDA), was evaluated based on the previous fire incidence in the study area. Analytic Hierarchy Process (AHP) method was used to generate fire risk map based on topographic features and forest vegetation structures. Then, total of 19 forest fires recorded in the study area in last 50 years were evaluated to validate the risk map. It was found that $23.81 \%$ of the area was subject to extreme risk, while $25.81 \%$ was of high risk. The results indicated that about $42.10 \%$ of the fire events fell into the forested areas with extreme fire risk, while $31,58 \%$ were in the high fire risk. Thus, the fire risk map developed by using the GIS-based MCDA can be an effective way for accurate estimation of the fire sensitive areas.
\end{abstract}

\section{INTRODUCTION}

It has increased pressures on forests that are fast growing and making demands on recent development. The most obvious reflections of this pressure on the forests are reflectivity, irregular cuttings and forest fires (Ertuğrul, 2005). Setting fires in forest lands causes ecological damage on vegetation and predictability in the forest (Bilici, 2009).

Classification of forests according to some principles in terms of fire provides precautionary benefits in the fight against forest fires. Fire risk classes are mainly determined by considering various risk factors, along with criteria such as the number of forest fires that broke out before and the area burned (Çanakçığlu, 1993). Fire risk is the probability of starting a fire due to the influence of the fire factors. The topographical features (i.e. slope and aspect) and vegetation structures (i.e. tree species, crown closure, and tree stage) have strong effects on fire risk (Carmel et al., 2009).

Other factors being equal, fires progress more quickly on steep terrain related with the wind behaviour. Besides, the spread rate of fire increases when the ground slope increases (Jaiswal et al., 2002). Fire risk also vary depending on the aspect. The south aspects are more suitable for fire as they receive direct sunlight which increases the temperature of the air and fuel material (Lin and Sergio, 2009).

Tree species is one of the important fire risk factors, considering their moisture content. Coniferous tree species such as Brutian pine with low humidity and highly flammable resin carry a high risk of fire due to their ability to ignite quickly. On the other hand, broad-leaved species such as beech with high humidity resists fires (Gazzard, 2012).

The crown closure of the forest is of great importance in terms of fire (Bilgili, 2003). Since forests consisting of the individuals with a density of $70 \%$ and more have fine fuel material with easy ignition feature, which may quickly result in hill fires and spread rapidly. On the other hand, it is difficult for the fire to peak in forests with less than $40 \%$ closure (Çanakçıŏlu, 1993). The young tree stages have high fire risk, while the risk diminished from the mature to over mature stages (Sağlam et al., 2008).

Fighting against forest fires is known as a difficult and costly work. In order to prevent forest fires and ensure adequate usage of the resources allocated for firefighting, fire risk zones in forest areas should be examined and regions with high fire risk must be determined. Thus, mapping of the fire risk zones is crucial for an efficient evaluation of forest fires (Jaiswal et al., 2002).

Geographic Information Systems (GIS) have significant potentials in fight against forest fires in terms of providing the opportunity to access and evaluate different data of large areas in a short time. By using GIS techniques in fight against forest fires, prediction and modelling of fires can be performed. (Erten et al., 2005).

GIS techniques integrated with MCDA method can provide effective solutions to complex spatial problems. AHP is a widely used MCDA method used in the forestry studies (Coulter et al., 2006). Previous studies indicated that GIS-based MCDA is a common method to estimate forest fire risk at low cost (Akay and Şahin, 2019). On the other hand, accuracy of the fire risk maps should be evaluated in order to ensure their benefits in fire management activities.

The main objective of the study was to validate the fire risk map based on the location and size of the forest fires. The risk map was developed by using GIS techniques integrated with AHP method considering specific fire risk factors. 


\section{MATERIAL AND METHODS}

\subsection{Study Area}

The study area was Yayla Forest Enterprise Chief (FEC) within the city of Balıkesir in Turkey (Figure 1). The average elevation and ground slope was $859.27 \mathrm{~m}$ and $24.96 \%$, respectively. The main tree species in the region were Black Pine, Brutian Pine, Oak, and Beech. The forest fires (19) that happened in Yayla FEC in last 50 years were evaluated.



Figure 1. Study area.

\subsection{Development of Fire Risk Map}

The GIS-based AHP method was employed to produce fire risk map with four risk rates: extreme, high, moderate, and low. For mapping fire risk zones, specified fire risk factors including topographical features (i.e. slope and aspect) and vegetation structures (i.e. tree species, crown closure, and tree stage) were considered. The climatic risk factors (i.e. precipitation, relative humidity, and wind) were not separately evaluated in this study because they were either represented under other factors (i.e. aspect) or they were uniform in the study area.

2.2.1. Digital Data Layers: The fire risk map was developed with ArcGIS 10.4.1 program using data layers of fire risk factors (slope, aspect, tree species, crown closure, and tree stage) with $10 \mathrm{~m}$ resolution. Data layers were generated by using the topographic map (1:25000) and forest management map (1:25000) of the study area, obtained from Dursunbey FED. The slope layer was generated by using Digital Elevation
Model (DEM) derived from contour lines (with $10 \mathrm{~m}$ intervals) of the topographical map. Then, slope map was reclassified into five classes including gentle (0-5\%), low (5-15\%), medium (15$25 \%)$, high $(25-35 \%)$, and very high $(>35 \%)$. The aspect map was produced based on the same DEM.

The data layers for the tree species or species compositions layers was produced by using the forest management map. The crown closure layer was divided into four classes: bare-land (0$10 \%)$, sparse $(10-40 \%)$, moderate $(40-70 \%)$, and dense $(>70 \%)$. Then, tree stages were divided into seven classes including newly plated, regenerated/young, young, young/mature, mature, mature/over mature, and over mature.

The forest management map was used to produce land use map of the study area. Then, the forest layer was generated by extracting the forest area which was used as the border of each digital data layer in the study.

2.2.1 AHP Method: After AHP method was introduced (Myers and Alpert, 1968), Saaty (1977) first developed its model. The AHP method evaluates a set of criteria and optimal solution is found among alternative options. In this study, the main criteria were specified fire risk factors (i.e. slope, aspect, tree species, crown closure, and tree stage). Decision maker's pairwise comparisons were implemented to compute a weights for criteria. In the process, the relative importance between two criteria was decided considering 1-9 numerical scale: equal importance (1), weak importance of one over another (3), essential or strong importance (5), demonstrated importance (7), absolute importance (9), intermediate values between the two adjacent judgments $(2,4,6,8)$.

The relative importance values among sub-criteria were determined according to fires risk. The lower score was given when the criterion was less important. The weighted averages were determined based on the normalized pairwise comparison matrix. A pairwise comparison matrix $A$ was generated to compute the weights for the sub-criteria. Each entry $\left(a_{j i}=1 / a_{i j}\right)$ of the matrix $A$ represents the importance of the $j$ th criterion relative to the $i$ th criterion. If $a_{j i}<1$, the $j$ th criterion is less important than the $i$ th criterion.

Secondly, normalized pairwise comparison matrix was produced. The column vector of $B$ was generated by using formula below (Gülci, 2014):

$$
b_{j i}=\frac{a_{j i}}{\sum_{j=1}^{n} a_{j i}}
$$

where $b_{j i}$ is each entry at the column and $n$ is the number of criteria. Then, weighted averages of the criteria $\left(w_{j}\right)$ were determined by averaging the entries on each row using formula below (Gülci, 2014)

$$
w_{j}=\frac{\sum_{i=1}^{n} c_{j i}}{n}
$$

Consistency Index $(C I)$ and Random Index $(R I)$ were also calculated to control the consistency of the evaluations made for the pairwise comparison matrices. The small value of this ratio $(<0.1)$ indicated that consistent results can be accomplished from the AHP method. 
In the next step, weighted average values $\left(\mathrm{w}_{\mathrm{j}}\right)$ was assigned to the corresponding criteria by using "Spatial Analyst" extension of ArcGIS 10.4.1. The "extAhp 2.0" tool was used to combine the weighted averages and compute the AHP scores. Finally, the forest layer in was classified into four fire risk classes.

\subsection{Validation of Fire Risk Map}

The previous forest fire locations were considered to validate the accuracy of the fire risk map. Total of 19 forest fires that happened (in 50 years) in the study area were selected by using the fire history data obtained from Yayla FEC. Then, the approximate locations of the selected forest fires were marked on the data layer of previous forest fires. The year and burned area for each forest fire were given in Table 1. The number of fires and burned areas for each fire risk class was evaluated in the validation process. The possible correlation between the size of the burned areas and fire risk class was also investigated.

\begin{tabular}{|c|c|c|}
\hline No & Burned Forest Area (Ha) & Year \\
\hline 1 & 13.0 & 1973 \\
2 & 1.2 & 1983 \\
3 & 4.0 & 1985 \\
4 & 0.2 & 1991 \\
5 & 0.5 & 1992 \\
6 & 0.05 & 1993 \\
7 & 0.1 & 1994 \\
8 & 0.02 & 1995 \\
9 & 0.005 & 1995 \\
10 & 0.2 & 1995 \\
11 & 0.01 & 1996 \\
12 & 0.03 & 1998 \\
13 & 1.0 & 1999 \\
14 & 0.1 & 1999 \\
15 & 0.1 & 2008 \\
16 & 8.0 & 2009 \\
17 & 0.2 & 2014 \\
18 & 0.06 & 2015 \\
19 & 108.0 & 2016 \\
\hline
\end{tabular}

Table 1. The data about the previous forest fires in Yayla FEC.

\section{RESULTS AND DISCUSSION}

\subsection{Fire Risk Factors}

It was found that the average elevation and the average height in the forest area was $893 \mathrm{~m}$ and $27.68 \%$, respectively. The ground slope map, generated based on DEM, was classified into five classes. The results indicated that about $32 \%$ of the area was on very high slope and about $22 \%$ was on high slope classes (Figure 2). Based on the previous studies, fire risk is higher on terrains with high ground slope (Jaiswal et al., 2002). The areas of medium, low, and gentle slope was about $22 \%$, $16 \%$, and $8 \%$, respectively.

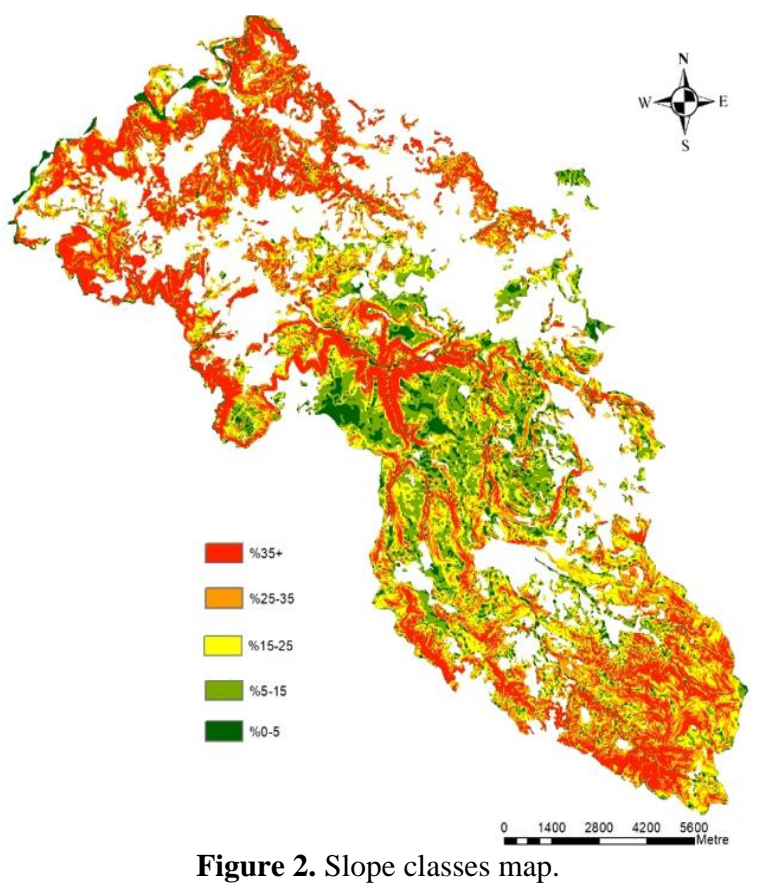

Based on the aspect map, derived from the DEM, about $35 \%$ of the study area was located on northern aspects. The proportion of south-facing aspects was about $30 \%$, which has higher fire risk due to high temperature and low humidity (Lin and Sergio, 2009).

The land use type map revealed that about $65 \%$ of the study area was forests, while the second largest land use type was agriculture (approximately 30\%). According to forest stand map, there were 21 tree species or species compositions in the study area. It was found that about $47 \%$ of the forest was covered with pure Black pine stand, while $4 \%$ was pure Brutian pine trees. About $14 \%$ of the forest was covered with pure oak stands. The deciduous trees are more resistant to forest fires, while the fire risk increases in stands consisted of coniferous trees (Gazzard, 2012).

Based on the crown closure map, it was found that $43 \%$ of the forest had dense closure, while $10 \%$ and $6 \%$ had moderate and sparse closure, respectively. The rest of the area was (41\%) bare-land. It was reported that forests with dense crown closure has the highest fire risk (Bilgili, 2003).

It was found that about $50 \%$ of the area was covered by mature tree stages (c). The tree stages at young and mature combination covered about $19 \%$ of the area (bc). The proportion of the areas covered with mature and overmature combination was about 10\% (Figure 3). The previous studies indicated that the fire risk is high at young generations (Sağlam et al., 2008).

\subsection{Fire Risk Map}

Fire risk map was generated based on GIS-based AHP method considering fire risk factors. The weighted values of ground slope criteria indicated that the steep slope had the highest values. In the case of aspect, south and southwest aspects had the highest values. 


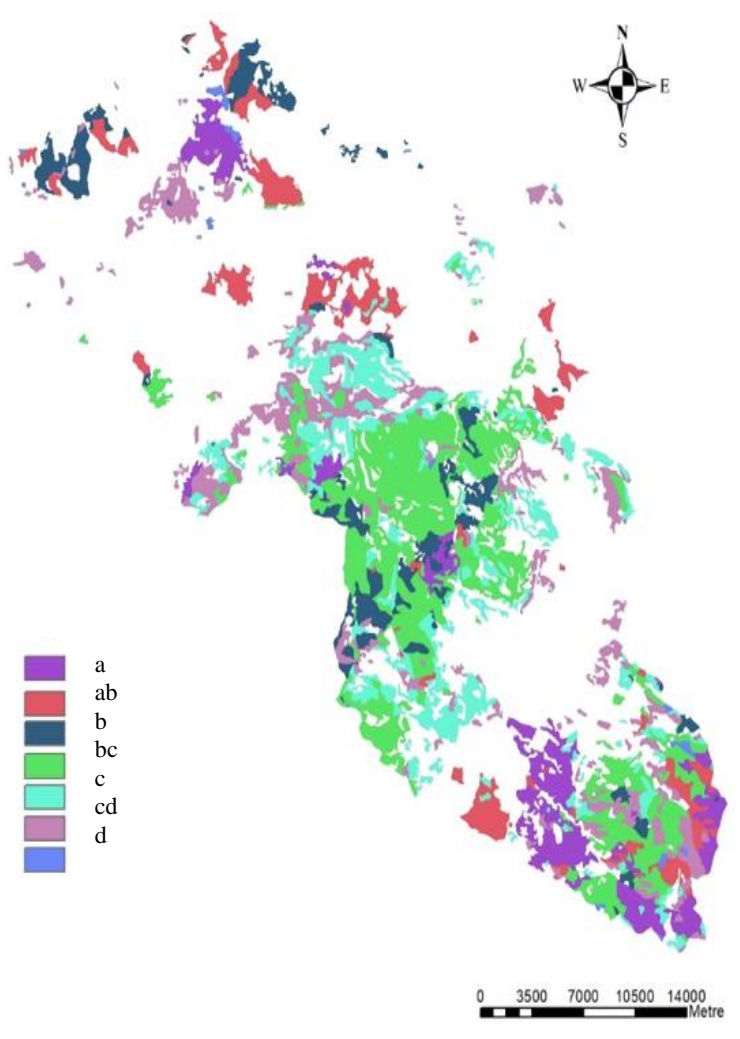

Figure 3. The tree stage map.
The pure coniferous forest had the highest weighted values while deciduous trees had the lowest weighted values. The weighted values of crown closure criteria indicated that forests with dense crown closure had the highest weighted values as reported in the literatures. For the tree stage criteria it was found that the young stages had the highest weighted values, while overmature stage had the lowest.

At the final stage, the weighted averages of the risk factors were combined. The forest fire risk map was produced by using "extAhp 2.0" tool. The weighted average values of each criterion was shown in Table 2 . The results indicated that the tree species was the most effective criterion and aspect was the least effective one.

\begin{tabular}{|c|c|}
\hline Criteria & Weighted Values \\
\hline Tree species & 0.28 \\
Crown Closure & 0.19 \\
Tree Stage & 0.22 \\
Slope & 0.19 \\
Aspect & 0.13 \\
\hline
\end{tabular}

Table 2. The weighted values of criteria.

The final forest fire risk map generated based on the GIS-based AHP method was indicated in Figure 4. It was found that about $24 \%$ of the forests were classified as extreme fire risk areas. About $26 \%$ and $32 \%$ of the forests were within the high and moderate fire risk classes, respectively.

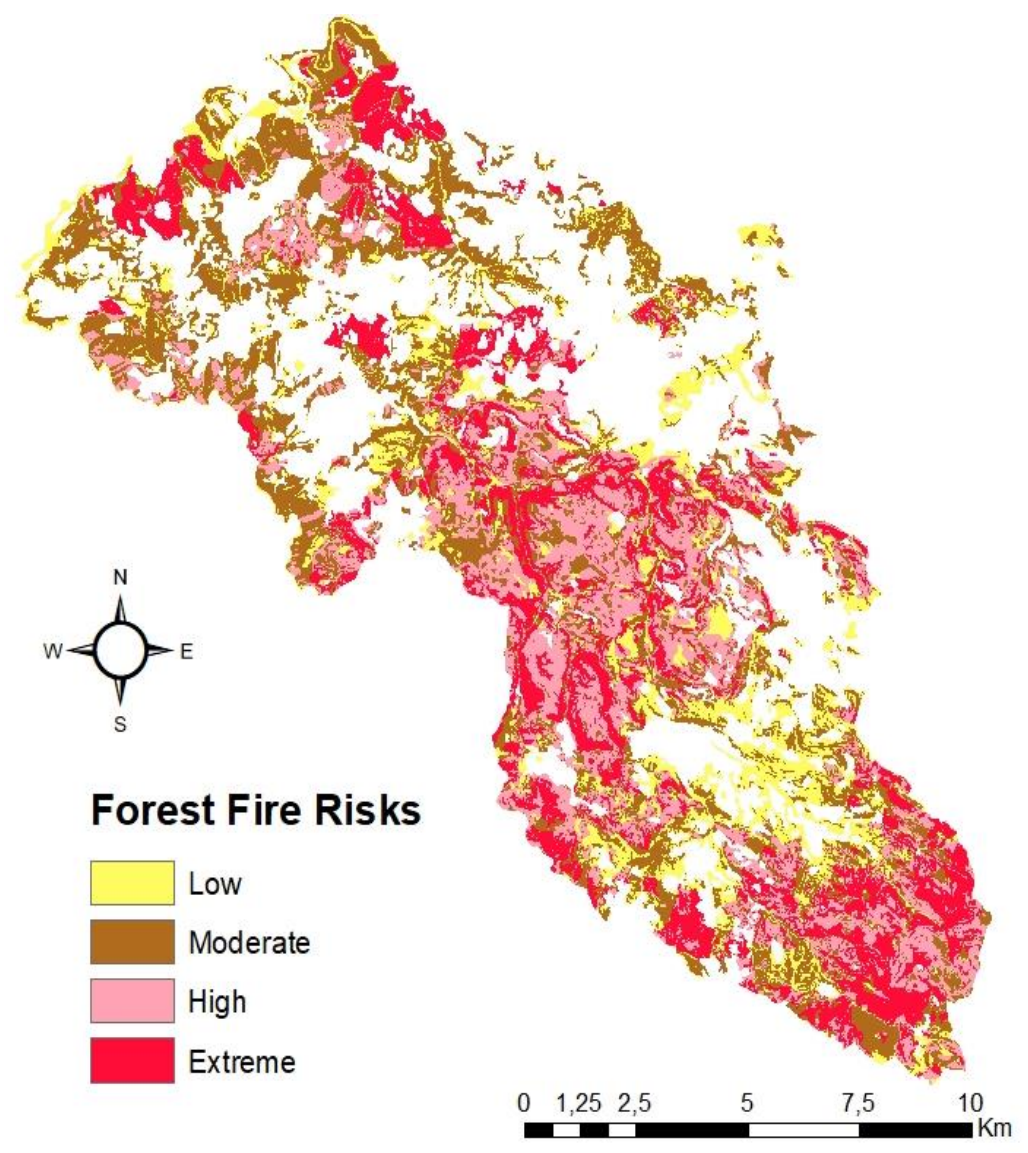

Figure 4. Forest fire risk map. 


\subsection{Accuracy of Fire Risk Map}

In order to control the validation of the fire risk map, previously happened forest fires (19) that happened in the study area in last 50 years were considered. The fire location map and fire risk map was overlapped and location of the fires were examined (Figure 5). The distribution of the fire locations is shown in Table 3. It was found that eight of the 19 fire events fell into the forested areas with extreme fire risk, while six fires were in the high fire risk. On the other hand, three and two fires were located in the forest areas with moderate and low fire risk zones, respectively.

\begin{tabular}{|c|c|c|}
\hline No & Burned Forest Area (ha) & Risk Class \\
\hline 1 & 13.0 & Low \\
2 & 1.2 & Low \\
3 & 4.0 & Moderate \\
4 & 0.2 & Moderate \\
5 & 0.5 & Moderate \\
6 & 0.05 & High \\
7 & 0.1 & High \\
8 & 0.02 & High \\
9 & 0.005 & High \\
10 & 0.2 & High \\
11 & 0.01 & High \\
12 & 0.03 & Extreme \\
13 & 1.0 & Extreme \\
14 & 0.1 & Extreme \\
15 & 0.1 & Extreme \\
16 & 8.0 & Extreme \\
17 & 0.2 & Extreme \\
18 & 0.06 & Extreme \\
19 & 108.0 & Extreme \\
\hline
\end{tabular}

Table 3. The fire risk class of the previous fires.

The correlation between the size of the fires and fire risk class was investigated using SPPS 16 program. The burned areas were evaluated under four groups: very small $(<0.1 \mathrm{ha})$, small (0.1-1.0 ha), medium (1.0-5.0 ha), and large ( $>5.0$ ha). Correlation analysis indicated that there was no statistically significant relationship between fire areas and fire risk classes. It was found that the average fire risk was the highest in the medium fire area, while it was the lowest in the very small fire area (Table 4). The forest fire that burned the largest forest area (108 ha) occurred in the forest with extreme fire risk class.

\begin{tabular}{|l|c|c|c|c|c|}
\hline Risk & $\mathrm{N}$ & Mean & Std. Deviation & Min & Max \\
\hline Very small & 6 & 2.67 & 1.03 & 1 & 4 \\
Small & 6 & 3.17 & 1.33 & 1 & 4 \\
Medium & 4 & 3.50 & 1.00 & 2 & 4 \\
Large & 3 & 3.00 & 0.00 & 3 & 3 \\
Total & 19 & 3.05 & 1.03 & 1 & 4 \\
\hline
\end{tabular}

Table 4. The average fire risk values for the fire area groups.

\section{CONCLUSIONS}

The fire risk analysis was conducted with GIS-based AHP method of forested areas and these areas were divided into four classes considering the fire risk levels. The fire risk map was generated based on specific risk factors including topographical features (i.e slope and aspect), vegetation structures (i.e. tree species, crown closure, and tree stage). The final fire risk map indicated that about $50 \%$ of the forests were classified as extreme fire risk and high fire risk, while $32 \%$ was within the moderate fire risk zones. Then, the accuracy of the fire risk map was evaluated based on the previous fires occurred in the study area. It was found that about $74 \%$ of the fire events fell into the forested areas with extreme and the high fire risk. It can be concluded that using GIS techniques integrated with AHP method can provide decision makers with quick and accurate method in determining the forested areas subject to high fire risk. Once the forested areas with high fire risk is determined, necessary facilities can be established in the region and precautionary measures can be taken.

\section{REFERENCES}

Akay, A.E., Şahin, H., 2019: Forest Fire Risk Mapping by using GIS Techniques and AHP Method: A Case Study in Bodrum (Turkey).European Journal of Forest Engineering, 5(1), 25-35.

Bilgili, E., 2003: Stand Development and Fire Behavior. Forest Ecol. Manag., 179, 333-339.

Bilici, E., 2009: A Study on the Integration of Firebreaks and Fireline with Forest Roads Networks and It's Planning and Construction (A Case Study of Gallipoly National Park). Istanbul University. Faculty of Forestry Journal Series: A, 59(2), 86-102.

Carmel, Y., Paz, S., Jahashan, F., Shoshany, M., 2009: Assessing fire risk using Monte Carlo simulations of fire spread. Forest Ecol. Manag., 257(1), 370-377.

Coulter, E.D., Coakley, J., Sessions, J., 2006: The Analytic Hierarchy Process: A tutorial for Use in Prioritizing Forest Road Investments to Minimize Environmental Effects. International Journal of Forest Engineering, 17(2), 51-69.

Çanakçığlu, H., 1993: Forest Protection. İstanbul: İstanbul University Publication.

Erten, E., Kurgun, V., Musaoglu, N., 2004: Forest Fire Risk Zone Mapping from Satellite Imagery and GIS a Case Study. XXth ISPRS Congress, Youth Forum, Editor(s): Orhan Altan, July 12-23, Istanbul, Turkey. pp. 33-39.

Ertuğrul, M., 2005: The Situation of Forest Fires in the World and in Turkey. ZKÜ Bartın Faculty of Forestry Journal, 7(7), 43-50.

Gazzard, R., 2012: Risk Management Control Measure: Toolkit for Practitioners and Advisors. UK Vegetation Fire Risk Management. $24 \mathrm{p}$. 
Gülci, N., 2014: Researches on precision forestry in forest planning. Ph.D. thesis, KSU, Kahramanmaraş. 264 p.

Jaiswal, R.K., Mukherjee, S., Raju, D.K., Saxena, R., 2002: Forest fire risk zone mapping from satellite imagery and GIS. International Journal of Applied Earth Observation and Geoinformation, 4 (2002), 1-10.

Lin, J., Sergio, R., 2009: A derivation of the statistical characteristics of forest fires. Ecological Modelling, 220, 898903.

Myers, J.H., Alpert, M.I., 1968: Determinant Buying Attitudes: Meaning and Measurement. Journal of Marketing, 32, 13-20.

Saaty, T.L., 1977: A scaling method for priorities in hierarchical structures. J Math Psychol., 15, 234-281.

Sağlam, B., Bilgili, E., Durmaz, B.D., Küçük, Ö., Kadığulları, A.İ., Küçük, Ö., 2008: Spatio-temporal analysis of forest fire risk and danger using LANDSAT imagery. Sensors, 8, 39703987. 